\title{
Silicon Microspheres for Terahertz Communication
}

Onur Akatlar and Ali Serpengüzel

Citation: AIP Conference Proceedings 899, 710 (2007); doi: 10.1063/1.2733451

View online: http://dx.doi.org/10.1063/1.2733451

View Table of Contents: http://aip.scitation.org/toc/apc/899/1

Published by the American Institute of Physics 


\title{
Silicon Microspheres for Terahertz Communication
}

\author{
Onur Akatlar and Ali Serpengüzel \\ Koç University, Microphotonics Research Laboratory, Physics Department, \\ Rumeli Feneri Yolu, Sariyer, Istanbul 34450 Turkey
}

\begin{abstract}
Silicon microspheres can be used for free space optical communication applications in the THz communication bands. The morphology dependent resonances of the microsphere have quality factors of 100000 , which provide the narrow linewidths for high resolution filtering, Raman lasers, modulators, and CMOS compatible detectors.
\end{abstract}

Keywords: microsphere, photonic atom, morphology-dependent resonance, terahertz, wavelength division multiplexing.

PACS: $42.25 . \mathrm{P}, 42.25 . \mathrm{Fx}, 41.20 . \mathrm{Jb}, 42.50 . \mathrm{Pq}, 42.55 . \mathrm{Sa}, 42.60 . \mathrm{Da}$

Morphology dependent resonances (MDR's) of $\mu$ spheres provide the necessary optical feedback for applications in spectroscopy [1]. $\mu$-spheres are uniquely applicable in compact optoelectronic devices for wavelength division multiplexing (WDM) [2].

In this work, we have investigated the mid-IR (THz) free space communication applications of silicon $(\mathrm{Si})$ $\mu$-spheres. Silicon has been the material of choice for the $\mu$-electronics industry for more than half-acentury, and is an inexpensive, plentiful, well understood material. The need for low cost photonic devices has stimulated a significant amount of research in Si photonics, which is currently less well developed as compared to III-V technologies, and is poised to make a serious impact on the telecommunications industry. Silicon $\mu$-spheres are a new paradigm for the use of silicon in optical communication applications.

Elastic light scattering spectra from a Si $\mu$-sphere with radius $\mathrm{a}=25 \mu \mathrm{m}$, and refractive index $\mathrm{m}=$ $3.4224+0.00003 \mathrm{i}$ are calculated. Forward $\left(0^{\circ}\right)$, perpendicular $\left(90^{\circ}\right)$, and backward $\left(180^{\circ}\right)$ elastic scattering spectra are calculated. In the calculations, a plane wave is incident on a $\mathrm{Si}$ microsphere of radius $25 \mu \mathrm{m}$ and a refractive index $\mathrm{m}=3.4224+$ $0.00003 \mathrm{i}$. TE represents the plane wave with parallel and TM with perpendicular $\left({ }^{\perp}\right)$ polarization to the scattering plane. Due to spatial symmetry, TE and TM components give the same results for $0^{\circ}$ and $180^{\circ}$ scatterings. But the $90^{\circ}$ scattering depends on TE and TM. At $90^{\circ}$ scattering only the even mode number (n) MDRs can be observed. Figure 1 illustrates the results of the backward $\left(180^{\circ}\right)$ scattering. The highest $\mathrm{Q}$ factor is on the order of $10^{5}$. The mode spacing is $0.27 \mu \mathrm{m}$, which correlates well with the calculated value of $0.25 \mu \mathrm{m}$. In the backscattering direction, there is no background.

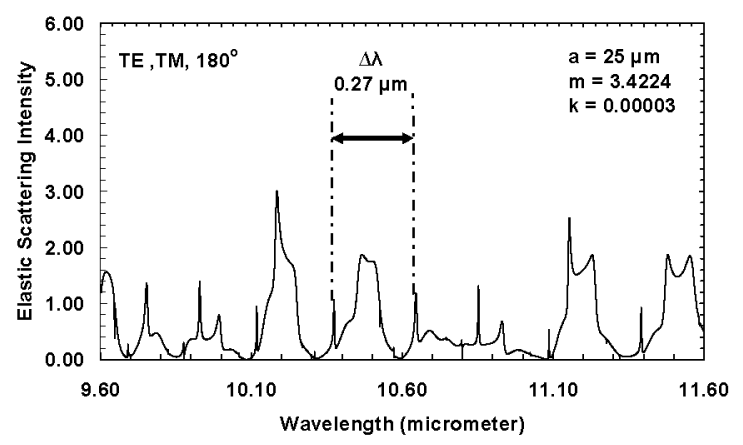

FIGURE 1. $180^{\circ}$ elastic scattering intensity.

In the forward direction there is a background in the spectrum due to the concentration of the incoming beam. With the proper system design, it would be possible to use Si $\mu$-spheres for space and earth based communication. The Si $\mu$-sphere shows promise as a building block for future electro-photonic integration in the mid-IR.

We would like to acknowledge the partial support of this research by the EC Grant No: FP6-IST-511616 PHOREMOST and FP6-IST-003887 NEMO.

1. K. J. Vahala, "Optical Microcavities", Nature, 424 839-846, 2003.

2. A. Serpengüzel, S. Arnold, G. Griffel, and J. A. Lock, J. Opt. Soc. Am. B., 14 790-795, 1997. 